\title{
Using Chain Extenders to Modify Release Rates of Orange Oil from Poly(Urea-Urethane) Microcapsules
}

\author{
Jurij Pušlar, $^{1, *}$ Dejan Štefanec $^{2}$ and Aljoša Vrhunec ${ }^{2}$ \\ ${ }^{1}$ Belinka Perkemija d.o.o., Zasavska cesta 95, 1231 Ljubljana-črnuče \\ ${ }^{2}$ MikroCaps d.o.o., Stražarjeva 14, 1000 Ljubljana \\ * Corresponding author: E-mail: jure.puslar@mikrocaps.com; \\ Phone: +386 59082 332; fax:+38659082334
}

Received: 16-02-2015

\begin{abstract}
Poly(urea-urethane) and polyurea microcapsules were prepared by an interfacial polymerisation using orange oil as a core material and a mixture of polymeric 4,4'-methylene diphenyl diisocyanate and toluene diisocyanate in a molar ratio of 1:0.2 as oil-soluble monomers. The membrane composition, thickness, and other properties were varied by changing the type and amount of oil-soluble monomers and water-soluble chain extenders, such as ethylenediamine and diethylenetriamine based on amine groups and 1,4-butanediol and polyethylene glycol 400 based on hydroxyl groups. Studies of the morphology and release behaviour show high dependency on the reaction conditions and reactants' properties. The release rate of the orange oil from microcapsules is highest when using a polymeric linear chain extender, polyethylene glycol with a molecular mass of 400. Microcapsules with improved mechanical stability and a slower release rate were obtained by a thicker membrane and by using the branched multi-functional chain extender diethylenetriamine.
\end{abstract}

Keywords: Microencapsulation, Interfacial polycondensation, Orange oil, Release behaviour

\section{Introduction}

Microencapsulation is typically used to enhance material stability, reduce adverse or toxic effects, improve handling properties, or extend the release of material for different applications. Microcapsules can be prepared by various methods and a combination of techniques. These are generally classified as chemical methods or physicochemical and physico-mechanical processes. ${ }^{1}$ The most widely used techniques are coacervation, ${ }^{2,-4}$ spray $\mathrm{dr}$ ying, ${ }^{5,6}$ in situ polymerisation, ${ }^{7}$ and interfacial polymerisation. ${ }^{8,9}$

In the literature much attention has been dedicated to interfacial polymerisation, in which a polymeric membrane is formed around the dispersed inner phase of an emulsion. The microcapsules are usually obtained from a water-in-oil or oil-in-water emulsion, where each phase typically contains one or more monomers. Due to the high functionality of the monomers, the polycondensation reaction is very rapid and the first membrane is formed at the interface. ${ }^{10}$ As soon as the polymer is for- med, it precipitates on one side of the interface, thus forming the primary membrane, and the reaction slows down because the diffusion of the monomers becomes restricted by the polymeric wall. The most common examples of this method are polyamides ${ }^{11,12}$ or polyurea/polyurethane microcapsules. ${ }^{13-16}$ A polyurea shell will be formed when di- or polyisocyanate reacts with amine, and a polyamide shell will be formed when acid chloride reacts with amine. When di- or polyisocyanate reacts with a hydroxyl group containing a monomer, a polyurethane shell is formed.

In many applications, including air fresheners, cosmetics, and textile and laundry detergents, microcapsules containing fragrance are used. ${ }^{17-19}$ The volatile nature of fragrances leads to their effect being lost very rapidly, but microencapsulation techniques allow the release time to be extended to several months. The microencapsulation of essential oils and flavours has also led to many novelty applications and allowed exposure to the beneficial effects of aromatherapy at home and in the workplace. The majority of commercially available microencapsula- 
ted fragrance systems are based on amino-formaldehyde systems,${ }^{20}$ which are under restrictions due to environmental policies. Microcapsules containing perfume or fragrance prepared by coacervation using gelatine and gum arabic have also been reported. ${ }^{21}$ Coacervation is efficient and can produce microcapsules with a broad range of sizes. However, a disadvantage of coacervation is that it is hard to avoid the formation of large aggregates of microcapsules in dispersion during preparation and storage as extremely sticky coacervate droplets frequently adhere to each other before complete phase separation. The polymers used in coacervation generally have low molecular masses, resulting in microcapsules with weak mechanical resistance as well. Therefore, a polyurethane-polyurea system prepared by interfacial polymerisation appears to be more attractive. The membrane of such a system has good mechanical properties, is chemically inert with a low tendency to form agglomerates and, finally, is formaldehyde-free.

The results of previous studies on polyurethane/urea microcapsules ${ }^{22-25}$ indicate that the process of interfacial polymerisation is very complex and many parameters affect the membrane formation. The chemical nature and concentration of the reactants, type of surfactants, emulsion properties, and reaction conditions have a significant effect on the physico-chemical properties of final microcapsules regardless of the type of active components in the core. Many applications require a very slow release rate and a long active life of the core material. In order to obtain a slower release rate the membrane's porosity has to be reduced, which is achieved by changing the composition of the membrane and, very often, by a lower polymerisation temperature. However, lower temperatures require longer reaction times to complete polymerisation, which can also increase the agglomeration of microcapsules and other limitations in largescale production.

This study investigated the properties of poly(ureaurethane) and polyurea microcapsules prepared by an interfacial polymerisation with various chain extenders in the aqueous phase, which were added at a higher temperature $\left(75^{\circ} \mathrm{C}\right)$ than in the conventional process $\left(20^{\circ} \mathrm{C}\right)$ in order to avoid agglomeration. Chain extenders with amine groups (ethylenediamine and diethylenetriamine) and hy- droxyl groups (polyethylene glycol 400 and 1,4-butanediol) were used. We investigated the microcapsule morphology, membrane structure, particle size distribution, and release behaviour of poly(urea-urethane) microcapsules using orange oil as an active ingredient. The effect of different membrane thicknesses on the microcapsule properties was also investigated.

\section{Experimental}

\section{1. Materials}

A mixture of $80 \%$ 2,4-toluene diisocyanate and $20 \%$ 2,6-toluene diisocyanate (TDI, trade name T80) with a functionality of 2 and equivalent weight of 87,1 from BorsadChem, a mixture of 4,4'-methylene diphenyl diisocyanate and homologues (pMDI, trade name Ongronat 2100) with a functionality of 2,7 and equivalent weight of 131,3 from BorsadChem, ethylenediamine (EDA) from Riedel-de Haen, diethylenetriamine (DETA) from Sigma-Aldrich, polyethylene glycol (PEG 400) from Sigma-Aldrich, 1,4-butanediol (BD) from SigmaAldrich were used to prepare the polyurethane-urea shell. Orange oil (Orange Oil sweet) from Frey\&Lau was used as the core material. Polyvinylalchohol (PVA, Celvol 205) from Celanese was used as a surfactant. Carboxymethylcellulose (CMC) from Acros Organics was used as the protective colloid. Dibuthyltindilaurate (DBTDL) from Sigma-Aldrich was used as a catalyst for the reaction of TDI and pMDI with PEG400 and BD. All chemicals were of technical grade.

\section{2. Microcapsule Preparation}

Polyurethane-polyurea microcapsules were prepared by interfacial polymerisation at the oil/water interface of the oil-in-water emulsion. The shell was formed by the reaction of TDI and pMDI with the chain extenders EDA, DETA, BD, and PEG400. The molar ratio of pMDI and TDI in the oil phase was 1:0.2 in all experiments. The oil phase (orange oil comprising a mixture of pMDI and TDI as shown in Table 1) was mixed with an aqueous phase 1 containing the surfactants. The aqueous phase 1 was composed of $250 \mathrm{~g}$ of water, $5 \mathrm{~g}$ of PVA,

Table 1. Composition of the oil phase and aqueous phase 2 of the emulsion

\begin{tabular}{|c|c|c|c|c|c|c|c|c|c|}
\hline \multirow[b]{2}{*}{ sample } & \multicolumn{3}{|c|}{ Oil phase } & \multicolumn{6}{|c|}{ Aqueous phase 2} \\
\hline & $\begin{array}{c}\text { Orange } \\
\text { oil (g) }\end{array}$ & $\begin{array}{c}\text { pMDI } \\
\left(10^{-2} \mathrm{~mol}\right)\end{array}$ & $\begin{array}{c}\text { TDI } \\
\left(10^{-2} \mathrm{~mol}\right)\end{array}$ & $\begin{array}{l}\text { Water } \\
(\mathrm{ml})\end{array}$ & $\begin{array}{c}\text { EDA } \\
\left(10^{-2} \mathrm{~mol}\right)\end{array}$ & $\begin{array}{c}\text { DETA } \\
\left(10^{-2} \mathrm{~mol}\right)\end{array}$ & $\begin{array}{c}\text { PEG400 } \\
\left(10^{-2} \mathrm{~mol}\right)\end{array}$ & $\begin{array}{c}\text { BD } \\
\left(10^{-2} \mathrm{~mol}\right)\end{array}$ & $\begin{array}{c}\text { DBDTL } \\
\text { (g) }\end{array}$ \\
\hline A1 & 100 & 0.86 & 0.17 & 10 & 3.33 & & & & \\
\hline $\mathrm{A} 2$ & 100 & 1.27 & 0.25 & 10 & 3.33 & & & & \\
\hline A3 & 100 & 1.41 & 0.28 & 10 & 3.33 & & & & \\
\hline B1 & 100 & 1.41 & 0.28 & 10 & & 1.94 & & & \\
\hline $\mathrm{C} 1$ & 100 & 1.41 & 0.28 & 30 & & & 2.2 & & 0.5 \\
\hline D1 & 100 & 1.41 & 0.28 & 30 & & & & 3.33 & 0.3 \\
\hline
\end{tabular}


and $5 \mathrm{~g}$ of $\mathrm{CMC}$, and was the same for all experiments. The mixed solution was then mechanically emulsified with an IKA homogeniser (model T25 digital) at 15,000 rpm for 4 minutes at room temperature to obtain stable emulsion-type oil-in-water. The emulsion was then transferred into a $500 \mathrm{~mL}$ polymerisation reactor with a controlled temperature and equipped with an overhead mechanical stirrer. The emulsion was mixed with the stirrer at $200 \mathrm{rpm}$ and heated to $75^{\circ} \mathrm{C}$. The heating time from room temperature to $75^{\circ} \mathrm{C}$ was 45 minutes. Aqueous phase 2 was added at $75{ }^{\circ} \mathrm{C}$. The compositions of aqueous phase 2 are shown in Table 1. All monomers in aqueous phase 2 were in an excess with regard to isocyanates in the oil phase. After 2 hours of mixing and heating at $75^{\circ} \mathrm{C}$, the resulting dispersion of the microcapsules was cooled to $25{ }^{\circ} \mathrm{C}$ and further characterised. The reaction procedure and temperatures were the same for all experiments mentioned in Table 1.

\section{3. Characterisation Techniques}

\section{Scanning electron microscopy (SEM)}

Scanning electron microscopy images were taken on a JSM-6060LV JEOL electron microscope. A drop of the suspension was placed on double-sided tape, which was affixed to a SEM mount. After drying, the sample was sputtered with gold and examined at an accelerating voltage of $10 \mathrm{kV}$.

\section{Optical microscopy (OM)}

Microcapsules in the dispersion were analysed by optical microscopy using an Olympus BX43 microscope equipped with measurement software. A drop of the sample was placed on the microscope cover glass, diluted with water, and analysed using the transmitted light mode.

\section{Fourier Transform Infrared Spectroscopy (FTIR)}

FTIR spectra were recorded on a FT-IR spectrometer Spectrum 100, Perkin Elmer, in transmittance mode. Spectra were collected in the spectral range between 600 and $4000 \mathrm{~cm}^{-1}$ at a resolution of $4 \mathrm{~cm}^{-1}$. Before the measurements, the samples were dried in a laboratory oven at $50{ }^{\circ} \mathrm{C}$ for 2 hours and cooled in a desiccator.

\section{Mean particle size and particle size distribution}

The particle size distribution of the produced microcapsules was analysed by laser diffraction using a MICROTRAC-FRA9200 instrument.

\section{Gravimetric analysis}

Gravimetric analysis was used to measure the release rate of the orange oil from the microcapsules: $20 \mathrm{~g}$ of the microcapsule dispersion was placed in a petri dish with a $45 \mathrm{~mm}$ radius and dried at $50{ }^{\circ} \mathrm{C}$ in a laboratory oven. The weights of the samples were measured as a function of time for 84 days.

\section{Results and Discussion}

\section{1. Structure of the Microcapsules}

The oil phase suspended in the continuous aqueous phase contained orange oil, pMDI, and TDI, which reacted at the interface with hydroxyl groups to form polyurethane chains. In the first stage during the emulsion heating to $75{ }^{\circ} \mathrm{C}$, isocyanate groups reacted at the interface with water diffused from the aqueous phase due to the lack of other water-soluble monomers. Amino acid groups were produced as intermediates, which were unstable and dissociated into a chain with the amino group and carbon dioxide. Chains with the amino group reacted further with the isocyanate group to form a urea linkage. After the addition of aqueous phase 2 containing compounds with hydroxyl (PEG400, BD) or amino (EDA, DETA) groups, the reaction with isocyanate became dominant and polyurethane and/or polyurea chains were formed.

Poly(urea-urethane) and polyurea membrane formation was observed by FTIR spectroscopy (Figure 1). The isocyanate peaks at $2270 \mathrm{~cm}^{-1}$ were absent, indicating that no residual monomer in the organic phase remained in the microcapsule. As seen in Figure 1, the spectrum of poly(urea-urethane) microcapsules (Fig. 1B) shows absorption at $1740 \mathrm{~cm}^{-1}$ for the carbonyl group stretching of urethane and at $1690-1650 \mathrm{~cm}^{-1}$ for urethane-urea formation. From the IR spectrum of polyurea microcapsules (Fig. 1A) the presence of a characteristic peak at 1645 $\mathrm{cm}^{-1}$ (urea carbonyl) and absence of a peak at $1740 \mathrm{~cm}^{-1}$

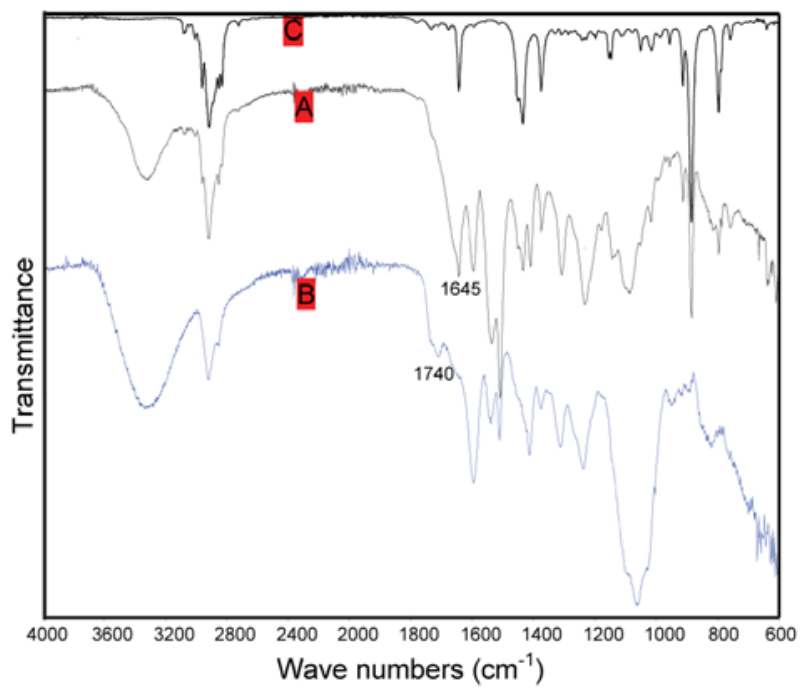

Figure 1. FTIR spectra of (A) the polyurea microcapsules, (B) the poly(urea-urethane) microcapsules, and (C) the core material (orange oil). 
(urethane carbonyl) is evident. The orange oil has a characteristic peak at $1644 \mathrm{~cm}^{-1}$. The characteristic peaks confirm that the wall membrane of the microcapsules prepared with EDA (A1, A2, A3) and DETA (B1) have a polyurea membrane and the microcapsules prepared with PEG400 (C1) and BD (D1) have a mixed polyurea/urethane membrane.

The IR spectrum also allows the conclusion that monomers in aqueous phase 2 reacted with isocyanate in the oil phase, even though aqueous phase 2 was added at $75{ }^{\circ} \mathrm{C}$ and the reaction of the isocyanates with the water had already taken place while heating (for 45 minutes) the emulsion from room temperature to $75^{\circ} \mathrm{C}$.

\section{2. Particle Size Distribution of the Microcapsules}

The particle size distributions of microcapsules are shown in Figure 2. All microcapsules are in the size range of $500 \mathrm{~nm}$ to $\sim 35 \mu \mathrm{m}$ with an average particle size between $5 \mu \mathrm{m}$ and $8 \mu \mathrm{m}$. The small peak appearing around the size 1.0-1.5 ìm are small capsules. This type of particle size distribution is typical for small (laboratory) systems with high shear mixing.

No capsule agglomerates were observed, which was also confirmed by optical microscopy and SEM microscopy (Fig. 3 and Fig. 4).

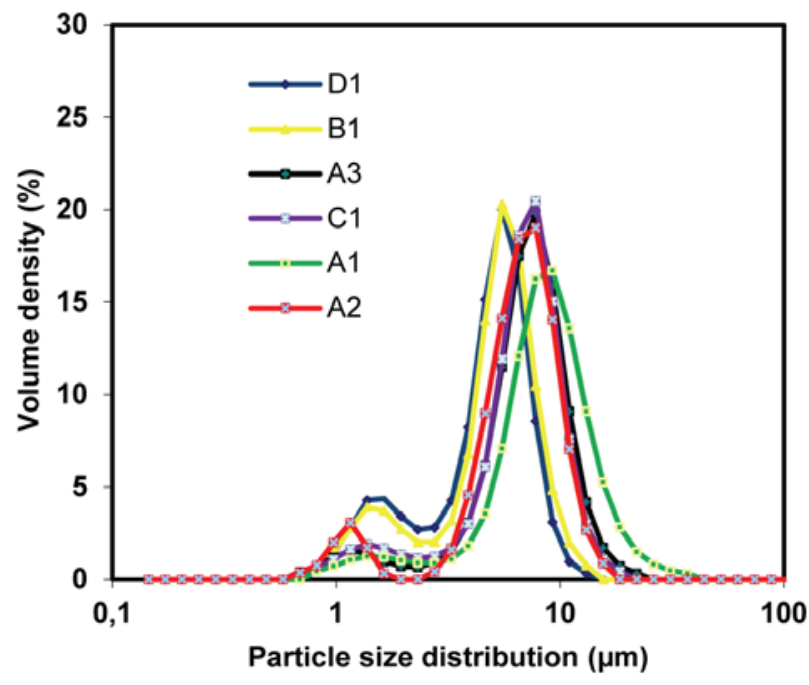

Figure 2. Particle size distribution of microcapsules differing in composition (A1, A2, A3, B1, C1, D1).

\section{3. Morphologies of the Microcapsules}

Figure 3 shows images from the SEM and optical microscopy of the microcapsules with a polyurea membrane prepared with different amounts of mixtures of pMDI and TDI isocyanates in the organic phase and EDA in aqueous phase 2 , resulting in different membrane thicknesses
(A1, A2, A3). The optical microscopy does not show any major differences between the samples with different membrane thicknesses. Obviously, microcapsules prepared with the lowest concentration of pMDI and TDI in the oil phase (A1) lost their round shape during preparation of the sample for the SEM analysis (drying and vacuuming in the microscope chamber), whereas samples (A2, A3) with a thicker membrane maintained round-shaped microcapsules. The samples with different membrane thicknesses have smooth surfaces and no holes/pores were observed.

SEM images of microcapsules prepared with different chain extenders with hydroxyl and amine end groups in aqueous phase 2 and the same quantity of isocyanate in the organic phase are shown in Figure 4. Microcapsules prepared with DETA (B1) maintained the most spherical shape among all of the samples, followed by the sample prepared with the EDA (A3), PEG400 (C1) and BD (D1). All samples had a smooth surface with no pores. The capsules with a thin and/or brittle membrane (A1) lost their original shapes during the sample preparation, while other samples kept their round shape. It is evident from the SEM images (Fig. 3 and Fig. 4) of samples A2, A3, B1, C1, and D1 that no capsules were broken during sample preparation, from which the good mechanical resistance and elasticity of the thicker membrane prepared with a mixture of pMDI and TDI (with a molar ratio of 1:0.2), regardless of the aqueous reactant type, can be inferred. The morphology of the samples with a thicker membrane (A2, A3, B1, C1, and D1) was also independent of the type of aqueous reactants. In all cases, a very smooth surface was obtained without pores or aggregates (Fig. 4).

Previous studies have shown that the chain extenders used in the aqueous phase have a great impact on the surface morphology. ${ }^{22,23,25}$ The molecular weight of polyol affects the morphologies of the poly(urea-urethane) microcapsules; the higher the molecular weight of the polyol, the smoother the surface of the microcapsules. In addition, the reaction temperature has a great effect on capsule morphology. Polyurea microcapsules prepared with various diamines added at room temperature have a rough surface, and capsule agglomerates were observed. ${ }^{26}$ The formation of agglomerates after amine addition was often observed in previous studies and therefore some research has already been done on how to prevent this. One solution was recently described in the patent literature, ${ }^{27}$ in which agglomeration is minimised by the reaction of an isocyanate with a guanidine compound followed by reaction with a polyfunctional amine.

However, our study explored how to affect capsule morphology with the reaction procedure and temperatures. When chain extenders were added to the reaction mixture after heating it up to $75{ }^{\circ} \mathrm{C}$, the microcapsules produced had a smooth surface and no holes/pores were observed (Fig. 4). 

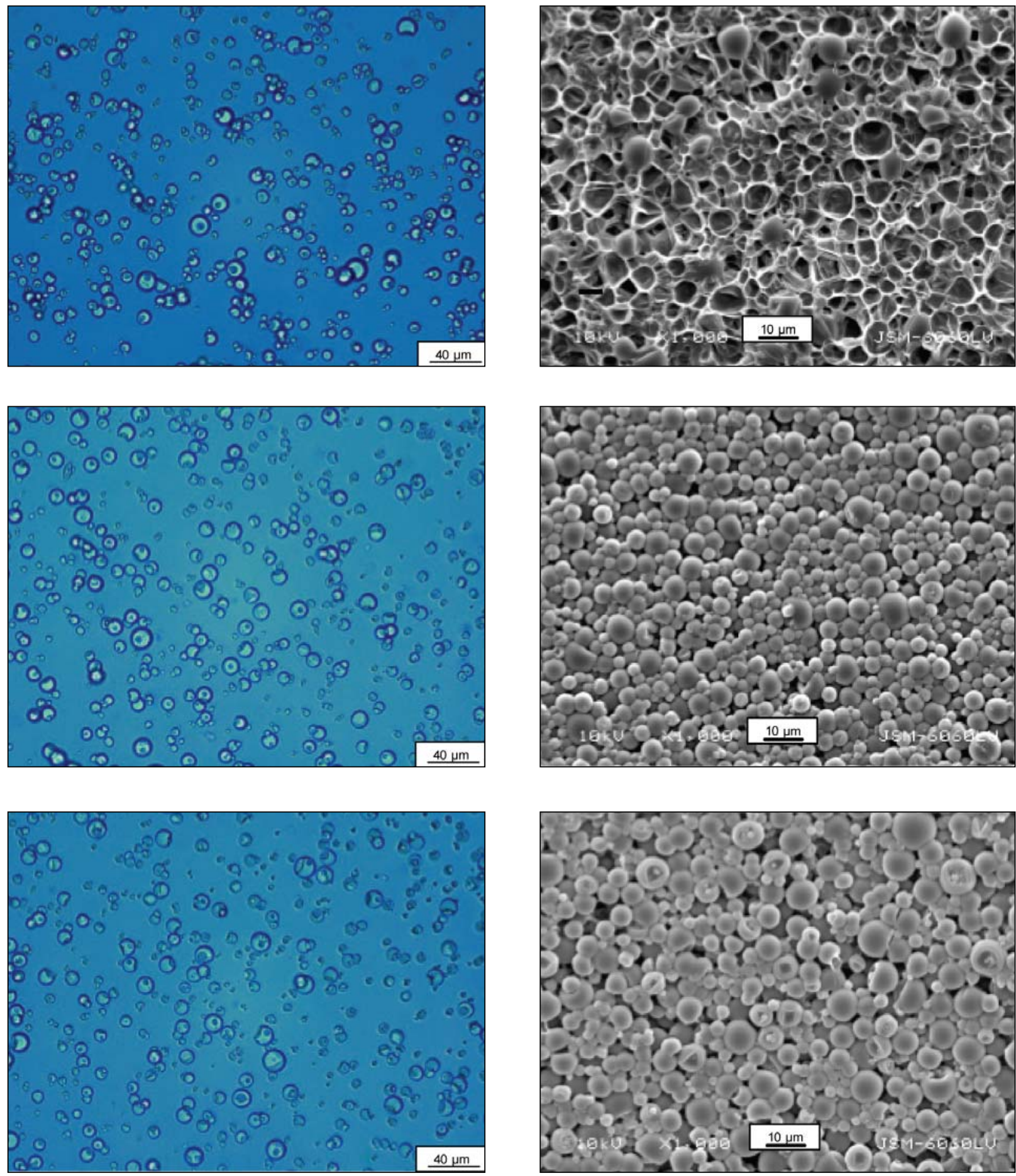

Figure 3. Optical microscopy (left) and SEM images (right) of the (polyurea) microcapsules with different membrane thicknesses (A1 $<$ A2 $<$ A3, for a description, see Table 1 and the text)

\section{4. Release Behaviour of the Orange Oil from the Poly(urea-urethane) Microcapsules}

Many physical properties of polyurethane-polyurea microcapsules, such as mechanical stability and the re- lease rate, can be affected by the thickness of the membrane, which may be controlled with a different quantity of di- and poly-isocyanates ${ }^{28}$ or the use of chain extenders in the water phase that differ in molecular mass, functionality, and/or structure. The release rate of the encapsulated material also depends on the emulsification ti- 

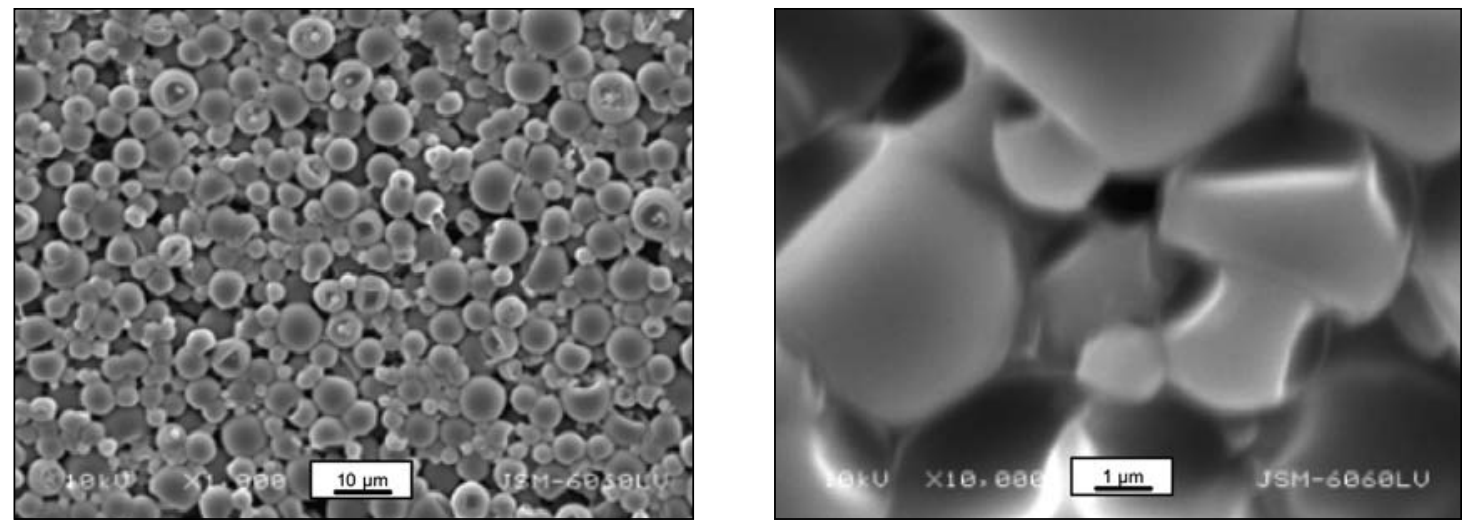

A3
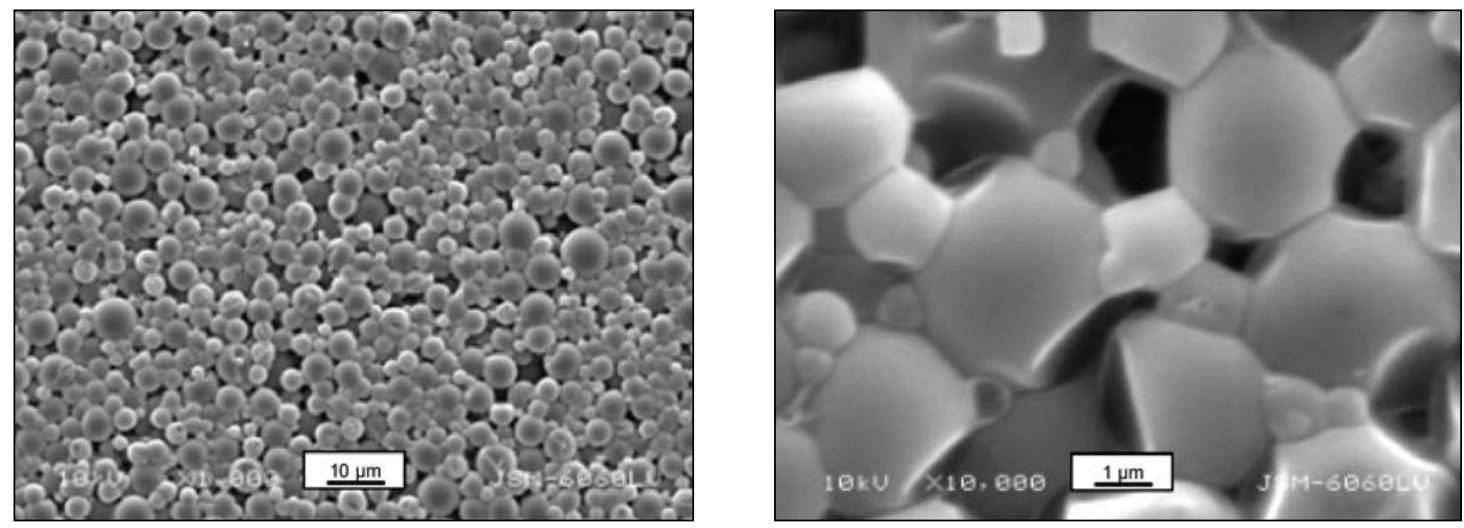

B1
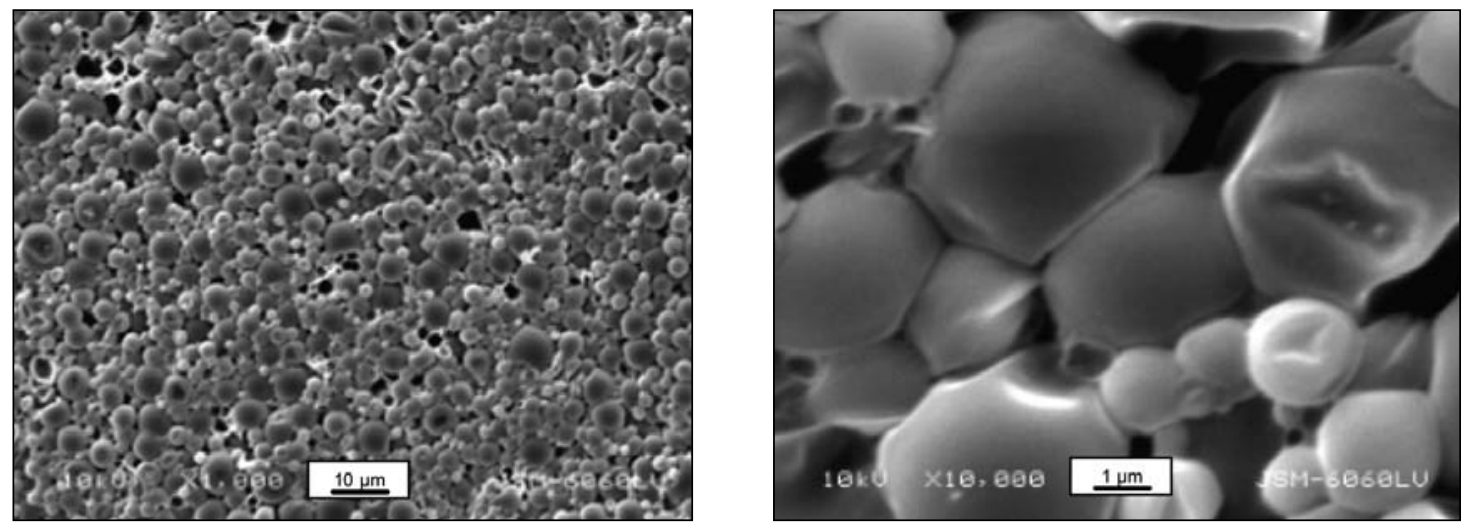

C1
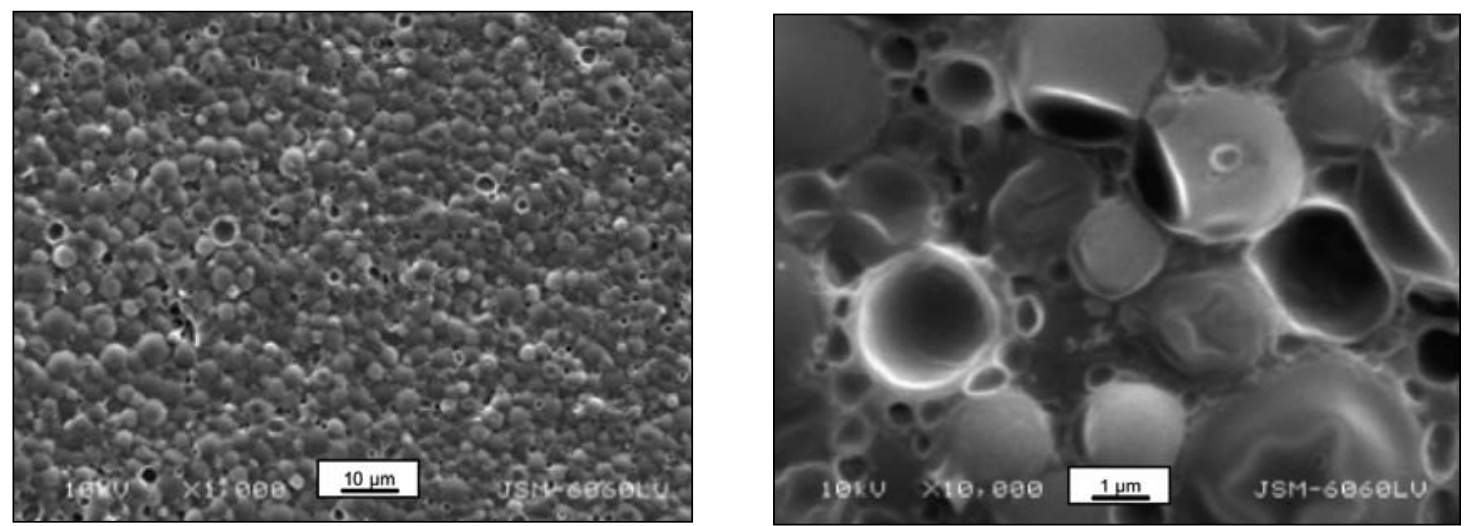

D1

Figure 4. SEM pictures of the poly(urea-urethane) microcapsules prepared with different chain extenders in aqueous phase 2 (A3_EDA, B1_DETA, C1_PEG400, D1_BD) 
me and stirring rate. ${ }^{29}$ In order to exclude the effects of these parameters, all of the described microcapsules were synthesised under the same emulsification time (4 minute) and stirring rate $(15,000 \mathrm{rpm})$. The percent release of orange oil from microcapsules was calculated from the total amount of orange oil in dry microcapsules and release of orange oil at the specified time from dry microcapsules.

Figure 5 shows the orange oil release curves for samples A1, A2, and A3, which were prepared with different quantities of mixture of pMDI and TDI isocyanate and a constant amount of the chain extender EDA. EDA was in excess with regard to the mixture of pMDI and TDI isocyanates. Sample A3 was prepared with the highest isocyanate concentration, whereas sample A2 contained $10 \%$ less and A1 $40 \%$ less isocyanate $\mathrm{NCO}$ groups than A3. FTIR spectroscopy confirmed the completion of the reaction in all three samples. The membrane thickness was expected to be proportional to the amount of pMDI and TDI. The orange oil release curves confirmed the fastest release rate of orange oil for the sample with the thinnest membrane (sample A1) and the slowest release rate for the sample with the thickest membrane (sample A3). These results show that the release rate of the orange oil from the microcapsules can be adjusted by the membrane thickness.

Release properties can also be modified by varying the type of chain extenders. When the EDA chain extender (sample A3) is replaced with a chain extender of higher functionality, such as DETA (sample B1), the release rate is much slower. Due to the higher functionality of

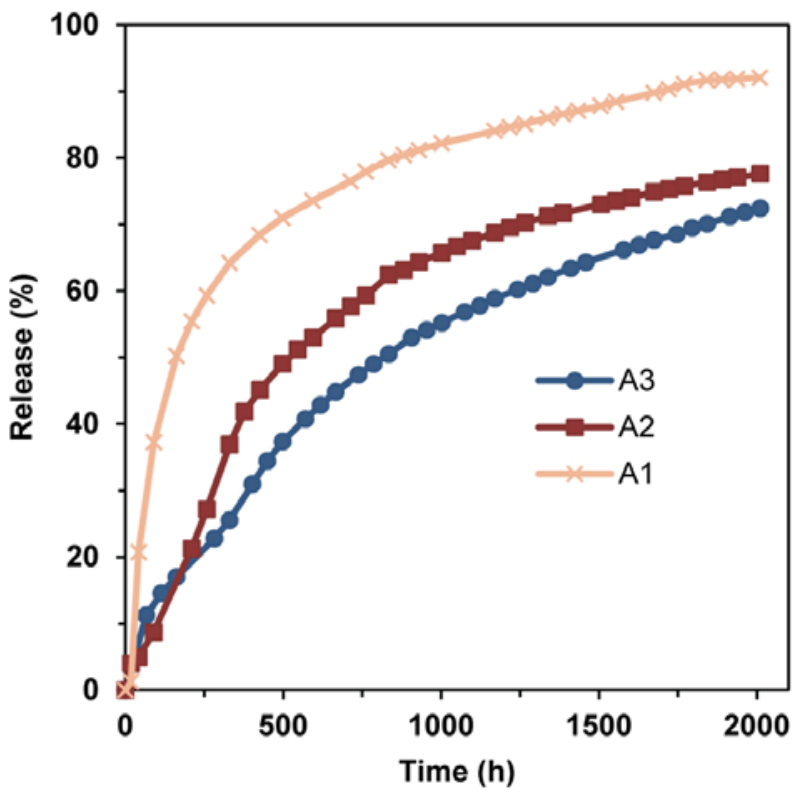

Figure 5. Release rate of the orange oil from the polyurea microcapsules with different membrane thicknesses $(\mathrm{A} 1<\mathrm{A} 2<\mathrm{A} 3)$ and chain extender EDA. The release was measured gravimetrically at $50{ }^{\circ} \mathrm{C}$ for 84 days.
DETA (functionality 3 instead of 2) a more extensive network with lower porosity is formed, resulting in an almost impermeable membrane (Figure 6).

In polyurethane/urea synthesis, monomers with functionality of 2 are very often used. Amines like EDA and reactants with hydroxyl groups like BD and PEG400 are low-molecular-weight chain extenders that are used to increase urethane and/or urea content in the final polymer, also resulting in different release properties. EDA has the lowest molecular weight $(60.10 \mathrm{~g} / \mathrm{mol})$, followed by BD $(90.12 \mathrm{~g} / \mathrm{mol})$ and PEG400 $(400 \mathrm{~g} / \mathrm{mol})$. We prepared samples with different chain extenders with a functionality of 2 and the orange oil release rate was measured (Figure 6). Samples C1 and D1 were prepared using chain extenders with hydroxyl groups, namely BD (D1) and PEG400 (C1), and sample A3 with EDA and amine groups. A faster release of orange oil was observed for sample $\mathrm{C} 1$ because the PEG400 molecules are longer and more flexible than the BD and EDA molecules, causing the higher-permeability PEG400 polyol chain to form soft segments of the backbone in the polyurethane/urea network, while the isocyanate forms hard segments with the hydroxyl or amine groups. The hard and soft segments in the polymer backbone are incompatible and tend to segregate into their own microdomains, which also contributes to the greater porosity of the polyurethane/urea membrane prepared with PEG400 as compared to BD. Sample A3, prepared with EDA, had a slower release than sample D1 prepared with BD and sample $\mathrm{C} 1$ prepared with PEG400. Differences between samples A3, C1, and D1 are seen in the molecular weight of the monomers, their molecule

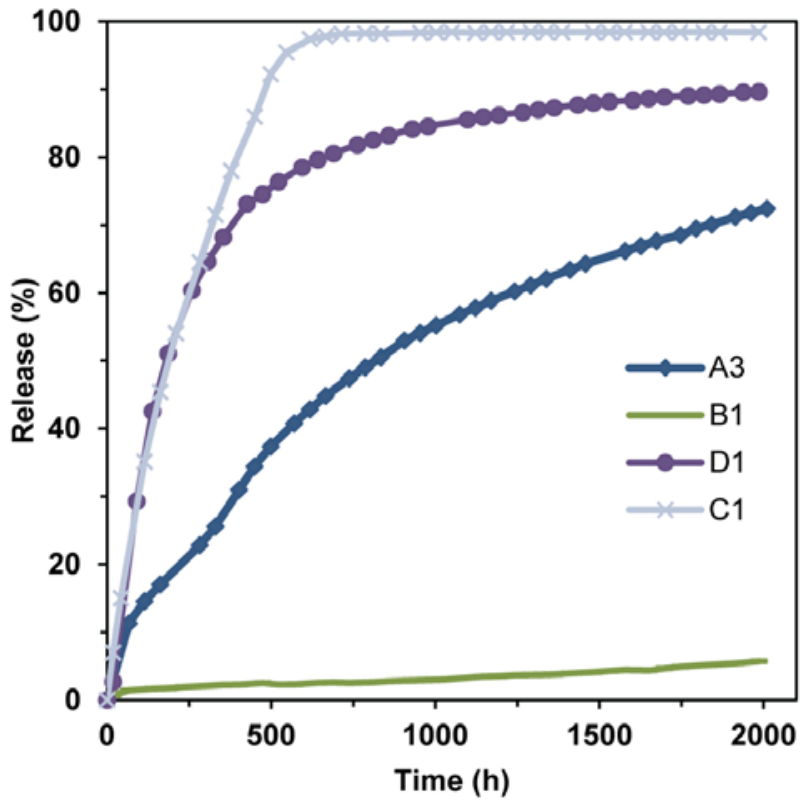

Figure 6. Orange oil release rate from microcapsules prepared with different chain extenders (EDA, DETA, PEG400, BD) in aqueous phase 2 . The release was measured gravimetrically at $50{ }^{\circ} \mathrm{C}$ for 84 days (A3_EDA, B1_DETA, C1_PEG400, D1_BD). 
chain length, and their membrane structure. Samples D1 and $\mathrm{C} 1$ have a polyurethane/urea structure and sample A3 has a polyurea structure (Fig. 6).

Previous work showed that a higher molecular weight of chain extenders with hydroxyl end groups in the aqueous phase resulted in a slower release rate of the active substance from microcapsules. ${ }^{22}$ In our case, chain extenders were added at a higher temperature and the results were the opposite. The higher the molecular weight of the chain extenders, the faster the release rate of the active substance.

\section{Conclusion}

Poly(urea-urethane) microcapsules containing orange oil were synthesised by interfacial polymerisation using a mixture of polymeric 4,4'-methylene diphenyl diisocyanate and toluene diisocyanate in a molar ratio of 1:0.2. Ethylenediamine, diethylenetriamine, polyethylene glycol 400, or 1,4-butanediol were used as chain extenders and were added at $75{ }^{\circ} \mathrm{C}$ to minimise the agglomeration of the microcapsules. It was shown that the release rate of the core component can be controlled by type of membrane: polyurea and poly(urea-urethane). The release rate of the orange oil from the microcapsules was affected by the thickness of the membrane and the type, functionality, and molecular weight of chain extender. The release rate of the orange oil from the microcapsules is the highest for the microcapsules with the thinnest walls (sample A1) or when using a chain extender with a higher molecular mass, such as PEG400 (sample C1). Microcapsules with a thicker membrane (samples A2 and A3) as well as those with chain extenders of higher functionality such as DETA (sample B1) and, consequently, a greater extent of crosslinking show better mechanical stability and a slower release rate.

\section{Acknowledgements}

The operation is partly financed by the European Union, the European Social Fund, and SPIRIT Slovenia (Public Agency of the Republic of Slovenia for the Promotion of Entrepreneurship, Innovation, Development, Investment and Tourism). We are grateful to Majda Žigon of the Slovenian Institute of Chemistry for her helpful advice.

\section{References}

1. S.K. Ghosh: Functional Coatings by Polymer Microencapsulation, Wiley-VCH, Weinheim, Germany, 2006, pp. 1-26. http://dx.doi.org/10.1002/3527608478.ch1

2. S. S. Deveci, G. Basal, Colloid Polym. Sci., 2009, 287, 1455-1467.

http://dx.doi.org/10.1007/s00396-009-2115-z
3. W. Li, G. Wu, H. Chen, M. Wang, Colloid Surface. A, 2009, 333, 133-137. http://dx.doi.org/10.1016/j.colsurfa.2008.09.046

4. I. Yutaka, H. Yuzi, O. Tsuneo, Microcapsule and process for production thereof, EP1118382, date of patent February 4, 2003.

5. A. Gharsallaoui, G. Roudaut, O. Chambin, A. Voilley, R. Saurel, Food Res. Int., 2007, 40, 1107-1121. http://dx.doi.org/10.1016/j.foodres.2007.07.004

6. J. G.Moreno, I. C. Herrera, J. M. Royo, J. C. Capuz, A. M. B. Simon, M. C. Franco, J. F. R. Romero, J. V. Palomino, Procedure for microencapsulation of phase change materials by spray-drying, EP2119498, date of patent November 18, 2009.

7. B. Šumiga, E. Knez, M. Vrtačnik, V. F. Savec, M. Starešinič, B. Boh, Acta Chim. Slov., 2011, 58, 14-25.

8. S. Girauda, S. Bourbigota, M. Rocherya, I. Vromana, L. Tighzertb, R. Delobelc, F. Poutchd, Polym. Degrad. Stabil., 2005, 88, 106-113. http://dx.doi.org/10.1016/j.polymdegradstab.2004.01.028

9. Y. H. Lin, C. S. Wei, Composition and method for fabricating microcapsules encapsulating phase-change material US Patent Number 7,833,578, date of patent July 7, 2003.

10. A. Markus, C. Linder in: S. Benita: Microencapsulation Methods and Industrial Applications, $2^{\text {nd }}$ Edition, Taylor \& Francis Group, New York, USA, 2006, pp. 55-78.

11. M. L. Soto-Portas, J. F. Argillier, F. Méchin, N. Zydowicz, Polym. Int., 2003, 52, 522-527.

http://dx.doi.org/10.1002/pi.1022

12. R. Dubey, T. C. Shami, K. U. B. Rao, H. Yoon, V. K. Varadan, VTT Symp., 2009, 18.

13. S. Giraud, S. Bourbigot, M. Rochery, I. Vroman, L. Tighzert, R. Delobel, J. Ind. Text., 2001, 31, 11-26. http://dx.doi.org/10.1106/3MUH-XYDA-NW2D-474D

14. K. Hong, S. Park, Mater. Sci. Eng. A-Struc, 1999, 272, 418421. http://dx.doi.org/10.1016/S0921-5093(99)00509-2

15. C. Liang, X. Lingling, S. Hongbo, Z. Zhibin, Energ. Convers. Manage, 2009, 50, 723-729. http://dx.doi.org/10.1016/j.enconman.2008.09.044

16. S. A. Hashemi, M. Zandi, Iran. Polym. J., 2001, 10, 265270.

17. S. N. Rodrigues, I. Fernandes, I. M. Martins, V. G. Mata, F. Barreiro, A. E. Rodrigues, Ind. Eng. Chem. Res., 2008, 47, 4142-4147. http://dx.doi.org/10.1021/ie800090c

18. G. Nelson, Int. J. Pharm., 2002, 242, 55-62. http://dx.doi.org/10.1016/S0378-5173(02)00141-2

19. H. Weber, W. Raehse, Washing and cleaning agents comprising fine microparticles with cleaning agent components, US Patent Number 7,601,678, date of patent August 7, 2003.

20. S. Bône, C. Vautrin, V. Barbesant, S. Truchon, I. Harrison, C. Geffroy, CHIMIA, 2011, 65, 177-181. http://dx.doi.org/10.2533/chimia.2011.177

21. S. Leclercq, C. Milo, G. A. Reineccius, J. Agric. Food Chem., 2009, 57, 1426-1432. http://dx.doi.org/10.1021/jf802472q

22. K. Hong, S. Park, React. Funct. Polym., 1999, 42, 193-200. http://dx.doi.org/10.1016/S1381-5148(98)00068-6 
23. Y. Frere, L. Danicher, P. Gramain, Eur. Polym. J., 1998, 34, 193-199. http://dx.doi.org/10.1016/S0014-3057(97)00084-0

24. M. Rafienia, F. Orang, S. H. Emami, J. Bioact. Compat. Pol., 2006, 21, 341-349. http://dx.doi.org/10.1177/0883911506066931

25. E. Jabbari, M. Khakpour, Biomaterials, 2000, 21, 2073 2079. http://dx.doi.org/10.1016/S0142-9612(00)00135-6

26. K. Hong, S. Park, Mater. Chem. Phys., 2000, 64, 20-24. http://dx.doi.org/10.1016/S0254-0584(99)00241-2
27. P. C. Yao, C. A. Cook, P. D. Rhoads, Method of preventing agglomeration during microencapsulation of fragrance oils, US Patent Number 20130313734 A1, date of patent November $28,2013$.

28. K. Choi, K. S. Min, I. H. Park, K. S. Kim, T. Chang, Polymer (Korea) 1990, 14, 392-400.

29. C. P. Chang, T. Yamamoto, M. Kimura, T. Sato, K. Ichikawa, T. Dobashi, J. Control. Release, 2003, 86, 207-211. http://dx.doi.org/10.1016/S0168-3659(02)00366-8

\section{Povzetek}

Z metodo medfazne polimerizacije smo pripravili poliuretansko-sečninske in polisečninske mikrokapsule. Za jedrni material smo uporabili pomarančno olje in kot monomera v organski fazi polifenilmetan-poliizocianat in toluen-2,4-diizociana v molskem razmerju 1:0.2. Preučevali smo lastnosti polimerne membrane mikrokapsul v odvisnosti od njene sestave, debeline in uporabe različnih podaljševal verig v vodni fazi. Kot podaljševala verig smo uporabili etilendiamin, dietilentriamin, 1,4 butandiol in polietilenglikol (PEG400). Ugotovili smo, da imajo reakcijski pogoji velik vpliv na morfologijo in hitrost sproščanja pomarančnega olja iz mikrokapsul. Sproščanje pomarančnega olja je bilo najhitrejše pri uporabi linearnega podaljševala verig polietilenglikol z molsko maso 400. Dobro mehansko odpornost in počasno sproščanje pomarančnega olja iz mikrokapsul pa smo dosegli z uporabo večfunkionalnega podaljševala verig dietilentriamin. 